\title{
Intra-operative local anaesthesia to reduce postoperative pain or distress in children after exodontia under general anaesthesia
}

\section{In paediatric patients does intra-operative local anaesthesia reduce postoperative pain?}

\author{
Coulthard P, Rolfe S, Mackie IC, Gazal G, Morton M, \\ Jackson-Leech D. Intraoperative local anaesthesia for paediatric \\ postoperative oral surgery pain - a randomized controlled trial. \\ Int J Oral Maxillofac Surg 2006; 35:1114-1119
}

Design A randomised controlled trial (RCT).

Intervention The appropriate drugs and dosage, namely $2 \mathrm{ml}$ of $2 \%$ lidocaine with 1:200 000 epinephrine (adrenaline), or placebo of $2 \mathrm{ml}$ of $0.9 \%$ sodium chloride, were administered by buccal infiltration injection adjacent to the teeth to be removed, after induction of general anaesthesia (GA).

Outcome measure Pain scores were recorded pre-operatively and after treatment upon waking, after $30 \mathrm{~min}$ and after $24 \mathrm{~h}$; distress scores were recorded pre-operatively, upon waking and after 30 min following treatment. Lip and cheek biting injuries were also recorded.

Results One hundred and forty-two children were recruited to the study and randomly allocated to one of the two groups. Data were incomplete for three children. There were no statistically significant differences between the mean pain scores for the local anaesthetic and placebo group pre-operatively, on waking from the GA, at $30 \mathrm{~min}$ postoperatively or after $24 \mathrm{~h}$. There were statistically significant increases in pain in both groups from pre-operative levels, with $13 \%$ of treatment and $12 \%$ of control patients recording severe pain and $13 \%$ of treatment and $10 \%$ of control patients recording very severe pain. These rates were similar at 30 min but reduced at $24 \mathrm{~h}$ following treatment. Lip or cheek biting injuries occurred in one control and three treatment patients.

Conclusions Intra-operative local anaesthesia has been found to be effective for pain control following a range of other surgical procedures, but we did not find it to be effective in reducing postoperative pain or distress in children after oral surgery.

Address for correspondence: Paul Coulthard, School of Dentistry,

University of Manchester, Higher Cambridge Street, Manchester M15 6FH, UK.

E-mail: paul.coulthard@man.ac.uk.

\section{Commentary}

Pain is a subjective experience, combining the perception of a noxious stimulus with a strong emotional component. A review of the recent literature from paediatric surgical disciplines suggests that local analgesia, via infiltration and block techniques, reduces postoperative pain in children undergoing surgery under GA. ${ }^{1}$ The dental literature is less conclusive. This study aimed to examine this issue.

A double-blind technique was used in this study of 142 children aged 4-12 years (median, 6 years) undergoing extraction of between one and 10 teeth (mean, 5.8 teeth) under GA. The children were randomised to receive either $2 \mathrm{ml}$ of $2 \%$ lidocaine with 1:200 000 adrenaline or $2 \mathrm{ml}$ of $0.9 \%$ normal saline as placebo injected by buccal infiltration adjacent to the site of dental extraction, after induction of GA. Details of the sample size calculation and randomisation method were reported. Although the number of participants for whom data were incomplete was reported, no reasons were given. The main clinical outcome measures were postoperative pain and distress and lip/ cheek biting over the first $24 \mathrm{~h}$ period. The authors used self-report of pain, choosing a reliable, valid paediatric visual analogue pain scale, in recognition of the significant personal and emotional component of the pain experience. ${ }^{2}$ All postoperative measures were recorded by the same investigator but it is not clear if the same dentist and anaesthetist treated all the participants.

The authors based their decision to use infiltration rather than regional block analgesia for lower extractions on a paper examining pain control in umbilical hernia repair. ${ }^{3}$ The local anaesthesia technique used in that study, long-lasting bupivicaine administered at completion of surgery, may not be directly comparable with the pre-operative lidocaine used in this study. No palatal local anaesthesia was used for upper extractions. Therefore the level of local anaesthesia fell short of that which would be given for exodontias in the awake child but mirrors that provided in most UK centres to children undergoing extractions under GA.

Disappointingly, the study found no statistically significant difference in pain or distress scores between the local anaesthesia and placebo groups. Indeed, high numbers of children (approx. one third of both groups) described "severe" or "very severe" pain 30 min after surgery. It is not clear whether these were the same children who had more than seven teeth extracted or were younger than 7 years old. The authors do not discuss the potential influence of emergence agitation on early postoperative assessment of distress in children, although the propofol/ sevoflurane general anaesthetic technique used may have minimised such an effect. ${ }^{4}$

Postoperative pain and distress following exodontia under GA is undoubtedly multifactorial, with outcome being influenced by factors such as pre-operative anxiety levels, systemic ${ }^{5}$ and local analgesia interventions, and the influence of GA. ${ }^{6}$ It would be ethically difficult to examine each factor independently. 
This well-designed RCT is a useful addition to the sparse paediatric dental literature on this subject. As the effectiveness of current local anaesthesia techniques associated with exodontia under GA remain unproven, future similarly designed trails examining the efficacy of pre-operative LA administered by the techniques standard for exodontia in the awake child would be welcome.

\section{Avril Macpherson}

Special Care and Sedation Department, NHS Lothian Salaried Primary Care Dental Service, Edinburgh, Scotland, UK

1. Morton N, Lonnqvist PA. Paediatric day-case anaesthesia and pain control. Curr Opin Anaesthesiol 2006; 19:617-621.
2. Turk DC, Melzack R. Handbook of Pain Assessment. New York: Guilford Press; 2000

3. Isaac LA, McEwen I, Hayes IA, Crawford MW. A pilot study of the rectus sheath block for pain control after umbilical hernia repair. Pediatr Anaesthesia 2006; 16:406-409.

4. Nakayama S, Furukawa $\mathrm{H}$, Yanai H. Propofol reduces the incidence of emergence agitation in preschool-aged children as well as in school-aged children: a comparison with sevoflurane. J Anaesthesia 2007; 21:19-23.

5. O'Donnell A, Henderson M, Fearne J, O'Donnell D. Management of post operative pain in children following extractions of primary teeth under general anaesthesia: a comparison of paracetamol, Voltarol and no analgesia. Int J Paediatr Dent 2007; 17:110-115.

6. Millar K, Asbury AJ, Bowman AW, Hosey MT, Musiello T, Welbury RR. The effects of brief sevoflurane-nitrous oxide anaesthesia upon children's postoperative cognition and behaviour. Anaesthesia 2006; 61:541-547.

Evidence-Based Dentistry (2007) 8, 5-6. doi:10.1038/sj.ebd.6400492

Key to evidence graphic used in the Evidence-based Dentistry Journal

The graphic is based on the Centre for Evidence-based Medicine levels of Evidence tables www.cebm.net/levels_of_evidence.asp (see Evidence-based Dentistry 2003;4: p 17-18)

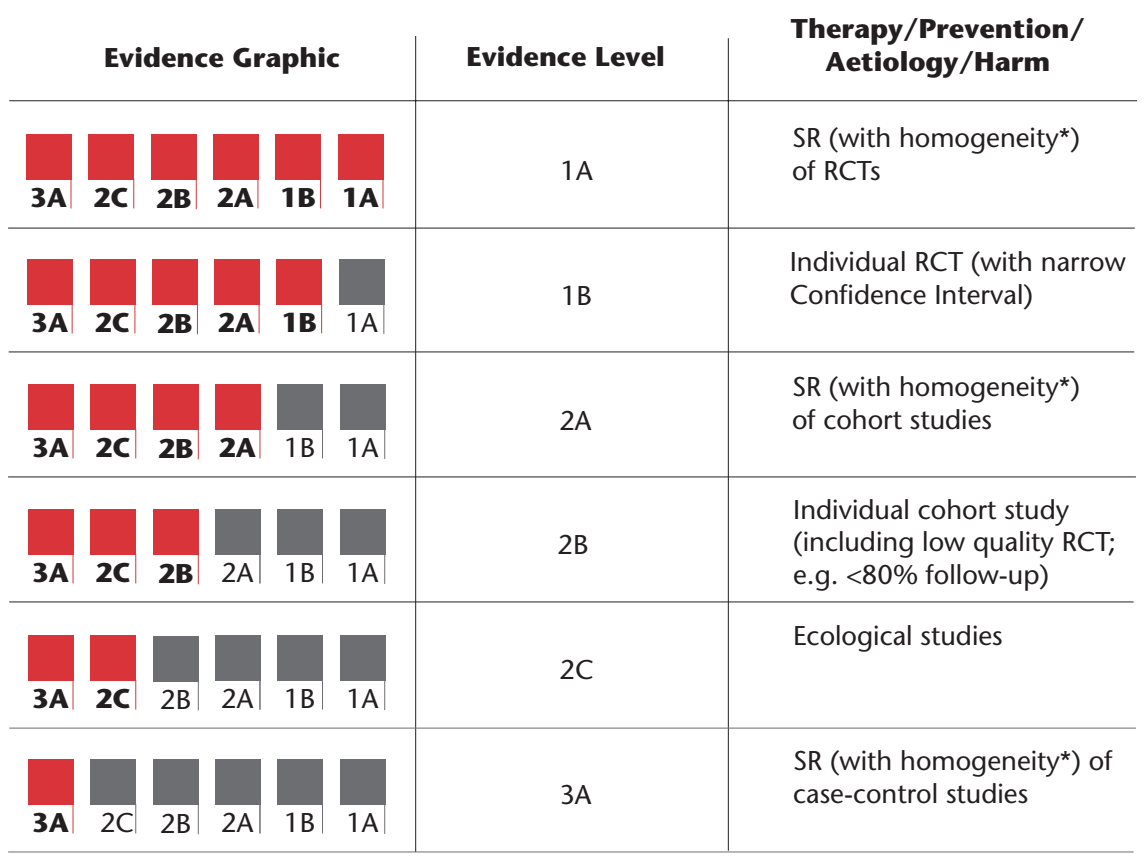

* By homogeneity we mean a systematic review that is free of worrisome variations (heterogeneity) in the directions and degrees of results between individual studies. Not all systematic reviews with statistically significant heterogeneity need be worrisome, and not all worrisome heterogeneity need be statistically significant. 